\title{
Faecal candida and diarrhoea
}

\author{
D Forbes, L Ee, P Camer-Pesci, P B Ward
}

Department of

Paediatrics, University of Western Australia, Princess Margaret Hospital for Children, GPO Box D184, Perth, Western Australia, 6001

D Forbes

Department of Microbiology, Princess Margaret Hospital for Children

P Camer-Pesci

P B Ward

Department of Gastroenterology, Princess Margaret Hospital for Children L Ee

Correspondence to: Prof. Forbes

david@paed.uwa.edu.au

Accepted 19 October 2000

\begin{abstract}
Background-Candida species are frequently isolated from stools of children with diarrhoea but are not proven enteropathogens. It is hypothesised that faecal candida causes diarrhoea.

Aims-To determine the prevalence of faecal candida in childhood diarrhoea and the relation between faecal yeasts and diarrhoea.

Methods-Comparison of clinical and laboratory data, including quantitative stool culture for yeasts from 107 children hospitalised with diarrhoea and 67 age matched controls without diarrhoea.

Results-Yeast species, predominantly candida, were identified in the stools of 43 children (39\%) with diarrhoea and 26 $(36 \%)$ without diarrhoea. The concentration of candida was positively associated with recent antibiotic use $(p=0.03)$ and with the presence of another enteric pathogen $(p<0.005)$, but not with patient age, nutritional status, or duration of diarrhoea.
\end{abstract}

Conclusion-Candida species do not cause childhood diarrhoea in well nourished children.

(Arch Dis Child 2001;84:328-331)

Keywords: diarrhoea; candida; yeasts

Despite the availability of effective therapy, diarrhoea still kills millions of children each year. ${ }^{1-3}$ Given the difficulties of bringing about social and economic changes necessary to reduce the incidence of gastroenteritis, there is a need to identify the microbial causes of the disease. In up to $40 \%$ of children with presumed infectious diarrhoea, no recognised pathogen can be identified. ${ }^{45}$ This may be due to our failure to appreciate the significance of certain intestinal microorganisms, such as yeasts.

Candida species form a ubiquitous genus of yeast present throughout the environment. They are part of the normal flora in the alimentary tract and on mucocutaneous membranes. ${ }^{6} C$ albicans is the most common yeast species isolated from human faeces, being identified in $65 \%$ of stool samples from healthy adults. ${ }^{7}$ Nevertheless, several reports have suggested that it may cause diarrhoea. These studies have identified candida, but not other enteric pathogens, in the stools of patients with diarrhoea and have reported symptom resolution following treatment. ${ }^{8-10}$ Candida has been identified in high concentrations in the stools of malnourished children, frequently with associated diarrhoea, ${ }^{11}{ }^{12}$ and it has been reported as the sole "pathogen" in the stools of children with diarrhoea. ${ }^{13} 14$ It has also been suggested as a cause of antibiotic associated diarrhoea in infants. ${ }^{15}$ The role of candida is therefore potentially important as the disease is common and potentially treatable.

A prospective, hospital based study was carried out to assess the prevalence and concentrations of candida and other yeast species in the stools of hospitalised children with and without diarrhoea. An attempt was made to identify factors predisposing to intestinal carriage of yeasts.

\section{Materials and methods}

The study was undertaken at Princess Margaret Hospital for Children, Perth, Western Australia, the tertiary paediatric centre for Western Australia. It was approved by the institution's Research and Ethics Committee.

\section{PATIENT SELECTION}

Stool specimens were obtained from children who were admitted to Princess Margaret Hospital for Children with diarrhoea or who developed diarrhoea while in hospital (diarrhoea group, DG). Control patients without diarrhoea were matched for age and selected from patients admitted to the same ward, and at the same time as the DG subjects (control group, CG). The majority of the CG children had acute respiratory infections. Clinical data collected prospectively included patient age, race, nutritional state (percentage weight for age), history of recent antibiotic usage, hydration status, duration of diarrhoea, stool characteristics, and evidence of oral or cutaneous candidiasis.

\section{SPECIMEN ANALYSIS}

All faecal specimens were examined for ova, cysts, parasites, fat globules, white and red blood cells, and cultured for salmonella, shigella, aeromonas, vibrio, campylobacter, and Clostridium difficile. $C$ difficile cytotoxin assay was carried out on cell culture using $C$ sordelli antitoxin to neutralise the cytopathic effect. Specimens from children with diarrhoea were also examined for rotavirus and adenovirus using latex particle agglutination (Diarlex, Australian Diagnostics). Culture of $C$ difficile or identification of $C$ difficile toxin was accepted as evidence of $C$ difficile infection.

All specimens were cultured for candida by diluting $0.2 \mathrm{~g}$ of faeces in $1.8 \mathrm{ml}$ of sterile saline solution. A $10 \mu \mathrm{l}$ aliquot was then plated on Sabouraud's dextrose agar (Oxoid CM41) containing $300 \mu \mathrm{g} / \mathrm{ml}$ chloramphenicol (Parke Davis Australia) and $10 \mu \mathrm{g} / \mathrm{ml}$ gentamicin (Rousell Laboratories Limited, England). Plate cultures for yeasts were incubated in air at $35^{\circ} \mathrm{C}$ for 48 hours before counting and identi- 
Table 1 Characteristics of diarrhoea and control patients

\begin{tabular}{lll}
\hline & Diarrhoea group $(D G) n(\%)$ & Control group $(C G) n(\%)$ \\
\hline $\begin{array}{l}\text { Number of subjects } \\
\text { Race }\end{array}$ & 107 & 67 \\
$\quad$ White & $81(76)$ & $52(78)$ \\
$\quad$ Aboriginal & $17(16)$ & $6(9)$ \\
Other & $8(8)$ & $7(10)$ \\
$\quad$ Unknown & 1 & $2(3)$ \\
Age & $24(22)$ & \\
$0-6$ mth & $20(19)$ & $25(37)$ \\
$>6-12$ mth & $57(53)$ & $16(24)$ \\
$>12-60$ mth & $1(1)$ & $21(31)$ \\
$>60$ mth & $5(5)$ & $1(2)$ \\
Unknown & $97($ SD $15 \%)$ & $4(6)$ \\
$\%$ weight for length & $48(45)$ & $99.8(\mathrm{SD} 14)$ \\
Antibiotic use & & $19(28)(\mathrm{p}=0.013)$ \\
\end{tabular}

Table 2 Enteric pathogens isolated from diarrhoea and control patients

\begin{tabular}{|c|c|c|}
\hline & $\begin{array}{l}\text { Diarrhoea group } \\
n(\%)\end{array}$ & $\begin{array}{l}\text { Control group } \\
n(\%)\end{array}$ \\
\hline & 107 & 67 \\
\hline \multicolumn{3}{|l|}{ Bacteria } \\
\hline $\begin{array}{l}C \text { difficile culture and/or } \\
\text { toxin }\end{array}$ & $28(26)$ & $6(9)$ \\
\hline Campylobacter jejuni & $4(4)$ & - \\
\hline \multicolumn{3}{|l|}{ Viruses } \\
\hline Adenovirus & $4(4)$ & —* \\
\hline Rotavirus & $20(19)$ & $一^{\star}$ \\
\hline \multicolumn{3}{|l|}{ Parasite } \\
\hline Giardia intestinalis & $6(6)$ & $2(3)$ \\
\hline Total & $62(58)$ & $8(12)$ \\
\hline
\end{tabular}

${ }^{\star}$ Rotavirus/adenovirus testing not performed on non-diarrhoeal stools.

fying the colonies. $C$ albicans was identified by the production of germ tubes and confirmed by the production of chlamydospores. ${ }^{16}$ Species identification of germ tube negative yeasts was carried out using the commercial API C20 AUX yeast kit (Blackaby Diagnostics, Australia). Yeast counts were determined by colony counting 48 hours after incubation.

STATISTICAL ANALYSIS

The significance of differences between the DG and CG patients was determined using the $\chi^{2}$ test for categorical variables and Student's $t$ test for continuous variables. Analyses are reported with all yeasts included together in one group.

\section{Results}

Stool samples were collected from 107 children with diarrhoea and 67 children without diarrhoea. Both groups were similar in age, race, and percentage weight for height (table 1). The duration of diarrhoea in the DG patients ranged from less than one day to 480 days, with a median of one day. The duration of diarrhoea in DG patients with and without stool yeasts was not significantly different (median: one day in both groups). More of the DG children had recent exposure to antibiotics than CG children $(\mathrm{n}=51,45 \%$ compared with $\mathrm{n}=19$, $28 \% ; \mathrm{p}=0.013)$.

Enteric pathogens were isolated from the stools of 47 of 107 (44\%) DG and seven of 67 (10\%) CG children (table 2). Twenty three of 66 patients with enteric yeasts also had other pathogens isolated from their stools (18 from DG and five from CG). There were five subjects in the DG in whom rotavirus and another pathogen was isolated. Identification
Table 3 Age distribution of patients with faecal yeasts

\begin{tabular}{|c|c|c|c|c|}
\hline & \multicolumn{2}{|c|}{ Diarrhoea group } & \multicolumn{2}{|c|}{ Control group } \\
\hline & $\begin{array}{l}\text { Total } \\
\text { patients } \\
n\end{array}$ & $\begin{array}{l}\text { Patients with } \\
\text { stool yeasts } \\
n(\%)\end{array}$ & $\begin{array}{l}\text { Total } \\
\text { patients } \\
n\end{array}$ & $\begin{array}{l}\text { Patients with } \\
\text { stool yeasts } \\
n(\%)\end{array}$ \\
\hline \multicolumn{5}{|l|}{ Patient age } \\
\hline$<1$ year & 46 & $19(37)$ & 41 & $17(24)$ \\
\hline $1-2$ years & 31 & 17 (39) & 11 & $4(18)$ \\
\hline$>2$ years & 30 & $7(20)$ & 15 & $5(27)$ \\
\hline Total & 107 & 43 & 67 & 26 \\
\hline
\end{tabular}

Table 4 Concentration of faecal yeasts

\begin{tabular}{lll}
\hline & $\begin{array}{c}\text { Diarrhoea group } \\
107 \text { subjects (\%) }\end{array}$ & $\begin{array}{l}\text { Control group } \\
67 \text { subjects (\%) }\end{array}$ \\
\hline $\begin{array}{l}\text { Yeast count } \\
<10000 \mathrm{cfu} / \mathrm{g} \text { stool }\end{array}$ & $9(8.4)$ & $14(20.9)$ \\
$>50000 \mathrm{cfu} / \mathrm{g}$ stool & $34(31.8)$ & $10(14.9)^{\star}$ \\
\hline
\end{tabular}

${ }^{\star} \mathrm{p}=0.009$

of an enteric pathogen was significantly associated with the identification of faecal yeasts $\left(\chi^{2}=25.1, \mathrm{p}<0.005\right)$.

There was no difference in the isolation of yeasts between DG $(n=43,39 \%)$ and CG ( $\mathrm{n}=26,35 \%)$ children. $C$ albicans was the most commonly identified yeast and was isolated from 35 of 107 (35\%) and 18 of 67 (27\%) DG and CG children, respectively. Other yeasts isolated included other candida species ( $C$ parapsilosis, $C$ guillermondii, $C$ lipolytica, $C$ humicola) as well as Torulopsis glabrata $(\mathrm{n}=2)$, Trichsporon beigelii $(\mathrm{n}=1)$, and Rhodotorula glutinis $(\mathrm{n}=1)$. All of the isolated yeast species were grouped together in subsequent analyses, and referred to collectively as yeasts.

Table 3 shows the age distribution of patients with yeasts in the stool. There was no significant association between age and identification of faecal yeasts.

Table 4 shows the concentration of stool yeasts. Patients with diarrhoea were more likely to have higher concentrations of faecal yeasts than the CG patients. The CG children tended to have more counts of less than 10000 yeasts per $g$ of faeces $\left(\chi^{2}=9.687, p=0.017\right)$. The concentration of faecal yeasts was significantly associated with use of antibiotics $\left(\chi^{2}=12.515\right.$, $\mathrm{p}<0.005)$.

Patients with yeasts in their stools were more likely to have had recent antibiotic treatment than those without yeasts, although this was not significant $\left(48 \%\right.$ v $35 \%, \chi^{2}=2.74$, $\mathrm{p}=0.095)$. The density of candida was however related to recent antibiotic use, with higher concentrations of faecal candida more likely to occur with recent antibiotic use $\left(\chi^{2}=11.687\right.$, $\mathrm{p}=0.009$ ).

Stool characteristics recorded included the presence of white blood cells (18 patients), red blood cells (two patients), fat globules (28 patients), lactose intolerance (17 patients), and monosaccharide intolerance (six patients). None of these characteristics were associated with the presence of stool yeasts.

\section{Discussion}

Yeasts and fungi, especially candida species, are present in the faeces of healthy individuals. Candida colonises the oral cavity of up to three 
quarters of preterm infants within the first week of life, ${ }^{17}$ and can be found in the oropharyx of nearly $20 \%$ of healthy infants. ${ }^{19}$ The gut is colonised more slowly, with $11 \%$ of preterm infants having positive faecal cultures for candida at 4 weeks of age. ${ }^{20} \mathrm{Up}$ to a quarter of healthy, non-hospitalised infants are reported to have candida in their faeces by 5 to 12 months of age. ${ }^{21}$ During childhood 12 to $16 \%$ of children carry candida in the stool, and the proportion increases to $80 \%$ in adulthood. ${ }^{7223}$ Hospitalised children appear to have higher carriage rates of candida than children in the community, and the proportion increases with duration of hospitalisation. ${ }^{22} 24$

This study confirms that yeasts, predominantly candida species, are common in the faeces of hospitalised patients in a paediatric hospital. Candida species were identified in the stools of approximately $40 \%$ of all patients studied. Although higher concentrations of candida were found in patients with diarrhoea it was not possible to prove a causative relation between the yeasts and diarrhoea.

A number of reports have suggested that candida might cause diarrhoea in adults and children. Discontinuation of antibiotics and the use of nystatin in adults with persistent diarrhoea and "heavy" faecal growth of yeasts resulted in a return to normal stool patterns within days. ${ }^{810}$ Gupta and Ehrinpreis identified heavy faecal growth of candida in a group of elderly, malnourished, and critically ill patients with diarrhoea, but were unable to find any other microbiological, inflammatory, or chemical cause for their symptoms. ${ }^{9}$ With anticandida therapy, the diarrhoea resolved. Danna et al reported resolution of antibiotic associated diarrhoea in elderly patients with intestinal overgrowth of candida, after treatment with nystatin. ${ }^{10}$

Bishop and Barnes identified $C$ albicans in the stools of one third of children with acute gastroenteritis who were aged less than 1 year, compared with just $15 \%$ of controls. ${ }^{25}$ They suggested that $C$ albicans was an opportunistic pathogen, causing prolonged diarrhoea after mucosal injury by another pathogen. ${ }^{25}$ Fungal mycelia in the stools were reported as a marker of invasive enteric candida in a group of patients, some of who had persistent diarrhoea following other infections. ${ }^{26}$ In these patients there was resolution of the diarrhoea after treatment with nystatin. In a group of Nigerian children, $77 \%$ had fungi isolated from the stools, and candida, the predominant isolate, was strongly associated with diarrhoea. ${ }^{13}$ In a large Indian study fungal proliferation was noted in the stools of $55 \%$ of children and adults with acute and chronic diarrhoea. ${ }^{27}$ The prevalence of faecal fungi in children peaked at the same time as the peak prevalence of bacterial diarrhoea. A subsequent study in India reported candida as the sole pathogen in $15 \%$ of diarrhoeal stool specimens. ${ }^{14}$ Prevalence was highest among infants aged $0-12$ months, with a summer peak in prevalence. Several authors have reported small intestinal overgrowth with candida in malnourished children. ${ }^{11}{ }^{12}$
In contrast to these previous studies, our study did not document an association between faecal candida species and diarrhoea. There are several explanations for this discrepancy. Firstly, earlier studies did not include control groups. Secondly, it is possible that candida may have a different effect in patients who are malnourished. Malnutrition may encourage proliferation of yeast species, and the association with diarrhoea may be coincidental.

It is not surprising that recent antibiotic use was associated with higher candida counts, given that antibiotic therapy encourages proliferation of candida in the intestine. ${ }^{28-30}$ Our finding that the identification of another pathogen was strongly associated with higher counts of faecal candida is also consistent with other reports. $^{12-142631}$

Despite previous reports to the contrary, we have not confirmed an association between faecal candida or other yeasts and diarrhoea. Faecal concentrations of candida were however higher in patients with diarrhoea. While candida did not contribute to diarrhoea in our population it is possible that in malnourished children with chronic diarrhoea, candida species may assume a significant role.

The assistance of the staff of the Microbiology Department at Princess Margaret Hospital, Perth, Western Australia in specimen processing, and ward nursing staff for their assistance in specimen collection is gratefully acknowledged.

1 Lambrechts T, Bryce J, Orinda V. Integrated management of childhood illness: a summary of first experiences. Bull World Health Organ 1999; 77:582-94

2 Ahmed T, Ali M, Ullah MM, et al. Mortality in severely malnourished children with diarrhoea and use of a standardised management protocol. Lancet 1999;353: 1919-22.

3 Murray CJ, Lopez AD. Mortality by cause for eight regions of the world: Global Burden of Disease Study. Lancet 1997; 349:1269-76.

4 Biswas R, Lyon D, Nelson E, et al. Aetiology of acute diarrhoea in hospitalized children in Hong Kong. Trop Med Int Health 1996;1:679-83.

5 Suwatano O. Acute diarrhea in under five-year-old children admitted to King Mongkut Prachomklao Hospital, Petchaburi Province. $\mathcal{F}$ Med Assoc Thai 1997;80:26-33.

6 Warren NG, Shadomy JH. Yeasts of medical importance. In: Warren NG, Shadomy JH. Yeasts of medical importance. In:
Balows A, Hausler WJ, Herrmann KL, et al, eds. Manual of clinical microbiology. Washington, DC: American Society for Microbiology, 1991:617-29.

7 Cohen R, Roth FJ, Delgado E, et al. Fungal flora of the human small and large intestine. N Engl F Med 1969;280: 638.

8 Kane JG, Chreteun JH, Garagusi VF. Diarrhoea caused by Candida. Lancet 1976;i:335-6.

9 Gupta TP, Ehrinpreis MN. Candida-associated diarrhea in hospitalized patients. Gastroenterology 1990;98:780-5.

10 Danna PL, Urban C, Bellin E, Rahal JJ. Role of candida in pathogenesis of antibiotic-associated diarrhoea in elderly inpatients. Lancet 1991;337:511-14.

11 Gracey M, Suharjono M, Sunoto M, Stone D. Microbial contamination of the gut: another feature of malnutrition. contamination of the gut: another

12 Heyworth B, Brown J. Jejunal microflora in malnourished Gambian children. Arch Dis Child 1975;50:27-33.

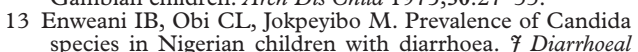
Dis Res 1994;12:133-5.

14 Chaudhury A, Nath G, Shukla B, et al. Diarrhoea associated with Candida spp: incidence and seasonal variation. $\mathcal{F}$ Diarrhoeal Dis Res 1996;14:110-12.

15 Ponnuvel KM, Rajkumar R, Menon T, Sankaranarayanan VS. Role of Candida in indirect pathogenesis of antibiotic associated diarrhoea in infants. Mycopathologia 1996;135: $145-7$.

16 Odds FC, Kibbler CC, Walker E, et al. Carriage of Candida species and $\mathrm{C}$ albicans biotypes in patients undergoing chemotherapy or bone marrow transplantation for haematological disease. $\mathcal{F}$ Clin Pathol 1989;42:1259-66.

17 Rotimi VO, Olowe SA, Ahmed I. The development of bacterial flora of premature neonates. F Hyg (Lond) 1985;94: terial flor

18 Pappu-Katikaneni L, Rao K, Banister E. Gastrointestinal colonization with yeast species and Candida septicemia in very low birth weight infants. Mycoses 1990;33:20-3. 
19 Dixon PN, Warin RP, English MP. Role of Candida albicans infection in napkin rashes. BMF 1969;2:23-7.

20 Ormala T, Korpin Ma tion with Candida or Pityrosporum sp. and serum Candida antigen in preterm neonates with very low birth weights. Scand F Infect Dis 1992;24:781-5.

21 Pederson G. Yeast flora in mother and child. A mycologicalclinical study of women followed up during pregnacy, the puerperium and 5-12 months after delivery, and their children on the 7th day of life and 5-12 months. Nord Med 1969;81:207.

22 Pan N-C, Pan I-H. Prevalence rate of Candida species in stool of children in Taipei. F Formosan Med Assoc 1964;63: 396.

23 Gorbach SL. Studies of intestinal microflora. I. Effects of diet, age and periodic sampling on numbers of faecal micro-organisms in man. Gastroenterology 1967;53:845-54.

24 Marks M, Marks S, Brazeau M. Yeast colonization in hospitalised and nonhospitalised children. F Pediatr 1975;87: talised

25 Bishop RF, Barnes GL, Townley RRW. Microbial flora of stomach and small intestine in infantile gastroenteritis. Acta Paediatr Scand 1974;63:418-22.

26 Kozinn P, Taschdiian C. Enteric candidiasis. Diagnosis and clinical considerations. Pediatrics 1962;30:71-85.

27 Talwar P, Chakrabarti A, Chawla A, et al. Fungal diarrhoea: association of different fungi and seasonal variation in thei incidence. Mycopathologia 1990;110:101-15.

28 Samonis G, Anaissie EJ, Rosenbaum B, Bodey GP. A model of sustained gastrointestinal colonization by Candida albicans in healthy adult mice. Infect Immun 1990;58:1514-17.

29 Samonis G, Gikas A, Anaissie EJ, et al. Prospective evaluation of effects of broad-spectrum antibiotics on gastrointestinal yeast colonization of humans. Antimicrob Agents Chemother 1993;37:51-3.

30 Guggenbichler JP, Kofler J, Allerberger F. The influence of third-generation cephalosporins on the aerobic intestinal flora. Infection 1985;13(suppl 1):S137-9.

31 Househam K, Mann M, Mitchell J, Bowie M. Duodenal microflora in infants with acute diarrheal disease. $\mathcal{F}$ Pediat Gastroenterol Nutr 1986;5:721-5.

\section{Commentary}

Does candida cause diarrhoea?

Despite significant progress over the years, no causative agent can be identified in a substantial proportion of infants and children with acute diarrhoea. In one study of over 4600 such children in Australia, no known enteric pathogen was found in $44 \%$ of cases. ${ }^{1}$ The search for possible pathogens goes on. In this study the authors asked whether Candida spp. or other yeasts might be an important and unrecognised cause of diarrhoea.

They analysed stool specimens from well nourished children in a tertiary referral hospital in Western Australia. These included children admitted with diarrhoea, children who developed diarrhoea while in hospital, and children without diarrhoea who were in hospital with various other disorders (disease controls). Although some of the subjects had chronic diarrhoea (the duration ranged from less than 24 hours to 480 days), the median duration was just one day. Yeasts (most often $C$ albicans) were identified in stool samples from $39 \%$ of those with diarrhoea and $35 \%$ of the controls (no significant difference). Higher yeast concentrations were reported in those with diarrhoea and in those with a history of recent antibiotic treatment. However, there was a higher incidence of antibiotic exposure in those with diarrhoea, and this may have explained that difference in concentration.
Here again the principle applies that "coincidence is no proof of causality". ${ }^{2}$ The association between antibiotic usage and diarrhoea is no surprise, and the link between antibiotic usage and faecal candida has been well documented. This, of course, is no proof that antibiotic associated diarrhoea is caused by candida. Nevertheless, there are anecdotal reports of successful treatment of this condition with nystatin.

Patients infected with human immunodeficiency virus often suffer from diarrhoea. $C$ albicans is commonly isolated from the stool in these patients, but is just one of many possible agents that might be responsible for the diarrhoea.

As the authors indicate, studies from Pakistan and Nigeria have revealed increased carriage of Candida spp. in the stools of malnourished children with diarrhoea. This does not confirm an aetiological role for candida, even in those populations. Candida spp. are frequently identified in the absence of diarrhoea as the present study confirms.

If "coincidence is not causality", neither does the failure of this study to show a significant association with diarrhoea disprove the role of yeasts as potential pathogens. There may be specific clinical circumstances in which they can be responsible for diarrhoea. In addition, there are more than 80 candida species, as well as other yeast species, and these may vary in their pathogenicity. Even within species certain strains may have different properties. Using restriction enzyme analysis and a $C$ albicans specific DNA probe, Mathaba et al recently identified specific genetically distinct strains that may be associated with diarrhoea. ${ }^{3}$ Increased levels of secretory proteinase production were noted in isolates from patients with diarrhoea. Variation in adherence properties was shown in different isolates, and they reported that reduced and increased adherence were associated with acute and chronic diarrhoea respectively.

The role of candida and other yeast species as enteric pathogens may yet prove to be a complex one.

M STEPHEN MURPHY

Institute of Child Health, Clinical Research Block, Whittall Street, Birmingham B4 6NH, UK

1 Barnes GL, Uren E, Stevens KB, Bishop RF. Etiology of acute gastroenteritis in hospitalized children in Melbourne, Australia, from April 1980 to March 1993. F Clin Microbiol 1998;36:133-8.

2 Heininger U. Coincidence is not causality-a principle which needs regular rediscovery. Arch Dis Child 2000;83: 355.

3 Mathaba LT, Paxman AE, Ward PB, Warmington JR. Genetically distinct strains of Candida albicans with elevated secretory proteinase production are associated with diarrhoea in hospitalised patients. $f$ Gastroentero Hepatol 2000;15:53-60. 